\title{
Original
}

\section{Evaluation of Cathepsin D Immunostaining in Colorectal Epithelial Tumors}

\author{
Masahiro WADA, Toshiaki Kunimura, Jun Usio, \\ Ryouji Hayashi, Kyoko Mastukawa, Masaski Matsukawa \\ and Toshio MorOHOSHI
}

\begin{abstract}
We evaluated the expression of cathepsin D (CD) in a series of colorectal tumor cells and stromal cells, in relation to the clinicopathological and histopathological features. Tissue samples were obtained from the archival surgical specimens of 72 primary colorectal adenocarcinomas and endoscopic mucosal resection (EMR) specimens of 53 colorectal adenomas and adenocarcinomas. The carcinomas were sited in the mucosa (M) in 23 patients, in the submucosa $(\mathrm{SM})$ in 28 patients, in the muscularis propria (MP) in 16 patients, and in the subserosa (SS) in 39 patients. The adenoma samples comprised 19 severe dysplastic adenomas (AD). High CD expression in the tumor cells was observed in 1 case $(5.3 \%)$ of $\mathrm{AD}, 2$ cases $(8.7 \%)$ of $\mathrm{M}, 10$ cases $(35.7 \%)$ of SM, 7 cases $(43.8 \%)$ of MP, and in 15 cases $(38.4 \%)$ of SS. There was a significant correlation between the $\mathrm{CD}$ expression of $\mathrm{M}$ and $\mathrm{SM}$ samples $(\mathrm{p}<$ 0.05). High CD expression in the stromal cells was observed in 1 case $(5.3 \%)$ of $\mathrm{AD}$, in 1 case $(4.3 \%)$ of $\mathrm{M}$, in 12 cases $(42.9 \%)$ of $\mathrm{SM}$, in 12 cases $(75 \%)$ of MP, and in 27 cases $(69.2 \%)$ of SS. There was correlation between the CD expression of $M$ and SM carcinomas $(p<0.01)$ and between that of SM and MP $(\mathrm{p}<0.05)$. In 72 surgical specimens, lymph nodes metastasis was proven histologically in 1 case $(5.9 \%)$ of SM, 2 cases $(12.5 \%)$ of MP, and in 17 cases $(43.6 \%)$ of SS. In both tumor cells and stromal cells, there were no correlation between $\mathrm{CD}$ expression and lymph nodes metastasis. These results indicate that cathepsin $\mathrm{D}$ expression in carcinoma and stromal cells reflects a potential for invasive growth of colorectal tumors.
\end{abstract}

Key words : colorectal tumor, adenocarcinoma, adenoma, cathepsin D, immunohistochemistry

\section{Introduction}

Degradation of the extracellular matrix and basement membrane that surrounds tumor cells is an essential step in the processes of tumor invasion and metastasis. This degradation and passage through the membrane is regulated largely by proteolytic enzymes ${ }^{1)}$. Cathepsin $\mathrm{D}(\mathrm{CD})$ is an aspartic lysosomal protease that is localized widely in tissues, and can digest extracellular matrix, including basement membrane components ${ }^{2)}$. A high level of $\mathrm{CD}$ in

First Department of Pathology, Showa University School of Medicine, 1-5-8 Hatanodai Shinagawa-ku, Tokyo 1428666, Japan. 
carcinoma cells has been associated with a poor prognosis, regardless of the presence or absence of lymph nodes metastasis, and this association has been confirmed in breast and laryngeal carcinoma ${ }^{3,4)}$. Normal stromal cells contain cathepsin D in their cytosol, and this pool of protein has been suggested to play a more important role in cancer progression than the $\mathrm{CD}$ in carcinoma cells ${ }^{5-7)}$.

There have been only a few reports describing the immunohistochemical expression ${ }^{8-11)}$ and intracytoplasmic localization of $\mathrm{CD}$ in colorectal tumors ${ }^{12)}$. Since the role of cathepsin $\mathrm{D}$ expression in predicting invasive potential has not been clarified, we evaluated the expression of this enzyme in a series of colorectal adenomas, adenocarcinomas and reactive stromal cells, and investigated any correlation with the associated clinical and histopathological features.

\section{Materials and Methods}

\section{Samples}

Tissue samples were obtained from the archival surgical specimens of 72 primary colorectal adenocarcinomas and endoscopic mucosal resection (EMR) specimens of 53 colorectal adenomas and adenocarcinomas. All samples were collected between 1997 and 2002 at Showa University Hospital. The patient age ranged from 40 to 87 years, with 89 males and 36 females. The specimens were fixed in $10 \%$ formalin for $24 \$ 8$ hours before embedding in paraffin. The carcinoma samples consisted of 69 well-differentiated adenocarcinomas and 37 moderately differentiated tubular adenocarcinomas, and based on a depth grading of tumor invasion, there were 23 carcinoma samples from the mucosa (M), 28 from the submucosa (SM), 16 from the muscularis propria (MP), and 39 from the subserosa (SS). Nineteen severe dysplastic adenomas (AD) were collected from patients with adenomas. The histological diagnoses were made according to the criteria of the Japanese Society for Cancer of the Colon and Rectum ${ }^{13)}$. Lymph nodes metastasis was defined as "positive" only when histologically proven.

\section{Immunohistochemistry}

Consecutive $3 \mu \mathrm{m}$ sections were dewaxed with xylene and rehydrated through a graded alcohol series. After quenching the endogenous peroxidase activity with absolute methanol containing $3 \% \mathrm{H}_{2} \mathrm{O}_{2}$, the sections were stained using the labeled streptavidin-biotin peroxidase complex technique (K0675, DAKO, Kyoto, Japan). A primary antibody against cathepsin D (CD, H908, NICHIREI, Tokyo, Japan) was applied for 18 hours at $4{ }^{\circ} \mathrm{C}$. The sections were colored with benzidine and lightly counterstained with hematoxylin for light microscopy.

Immunohistochemical evaluation. Arao et $a l^{12)}$ classified the immunoreactivity of colorectal epithelial cells into four types: no staining, granular staining at the supranuclear portion of the cytoplasm (Fig. 1A), granular staining at the basal portion of the cytoplasm (Fig. 1B), and diffuse staining throughout the cytoplasm (Fig. 1C). We designated the CD expressions as positive when the tumor cells showed the basal or diffuse type of staining. The immunostaining was compared by calculating the percentage of positive tumor cells in relation to the total number of cells of adenocarcinomas and adenomas. In each section, at least 10 high-power fields $(\times 400)$ were examined under light microscopy. CD immunohistochemical expression in reactive stromal cells was also evaluated (Fig. 2). In most cases the adjacent 

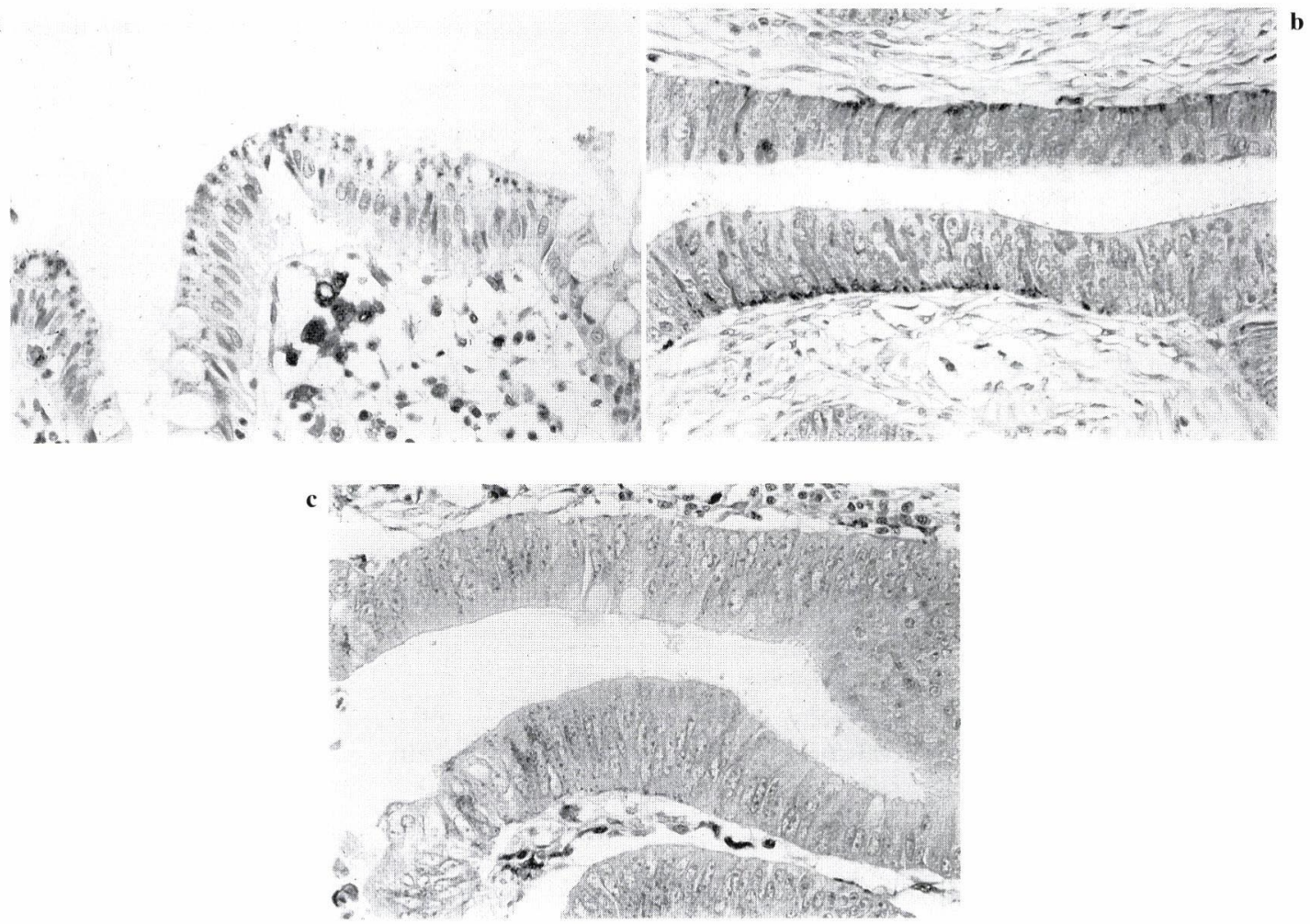

Fig. 1. Immunostaining of cathepsin D. A Granular staining at the supranuclear portion of the cytoplasm in ordinal colorectal mucosa. B. Granular staining at the basal portion of the cytoplasm in colorectal adenocarcinoma. C. Diffti8e staining throughout the cyioplasm in colorectal adenocarcinoma. Original magnification, $\times 400$.

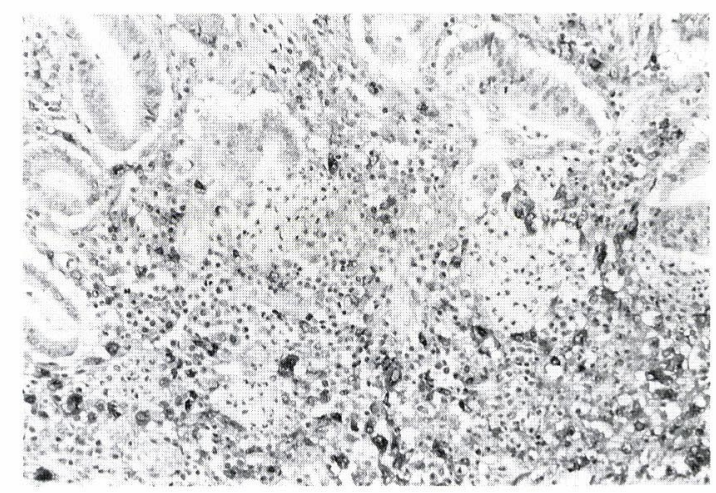

Fig. 2. Immunostaining of cathepsin D in ctromal celle observed in colorectal adenocarcinoma. Original magnification, $\times 200$. 
Table 1. High Cathepsin D Expression in correlation with clinicopathological features in colorectal tumors: Expression in Tumor and Stromal Cells

\begin{tabular}{|c|c|c|c|c|c|c|c|c|c|}
\hline & Severe dysplastic & & & & & enocarcin & ma & & \\
\hline & & & & & & th of inve & tion & & \\
\hline & & & M & & SM & & MP & & SS \\
\hline number & 19 & & 23 & & 28 & & 16 & & 39 \\
\hline Tumor cell & $1(5.3 \%)$ & NS & $2(8.7 \%)$ & $\mathrm{p}<0.05$ & $10(35.7 \%)$ & NS & $7(43.8 \%)$ & NS & $15(38.4 \%)$ \\
\hline Stromal oell & $1(5.3 \%)$ & NS & $1(4.3 \%)$ & $\mathrm{p}<0.01$ & $12(42.9 \%)$ & $\mathrm{p}<0.05$ & $12(75 \%)$ & NS & $27(69.2 \%)$ \\
\hline
\end{tabular}

Table 2. Relationship between High Oathepsin D Expression and Duke's Stage

\begin{tabular}{|c|c|c|c|c|c|}
\hline & \multicolumn{5}{|c|}{ Duke's stage } \\
\hline & A & & B & & $\mathrm{C}$ \\
\hline number & 20 & & 30 & & 22 \\
\hline Tumor cell & $9(45 \%)$ & NS & $13(43.3 \%)$ & NS & $9(40.9 \%)$ \\
\hline Stromal cell & $12(60 \%)$ & NS & $14(46.7 \%)$ & $\mathrm{p}<0.01$ & $20(90.9 \%)$ \\
\hline
\end{tabular}

normal mucosas were also examined. We separated the cases into two groups, such as "high CD" and "low CD", according to the percentage of positive tumor cells and nonneoplastic reactive stromal cells. The cut-off line was $10 \%$ for CD expression of tumor cells and $15 \%$ for $\mathrm{CD}$ expression of reactive stromal cells, as suggested by previous studies in macrophages ${ }^{11.14)}$.

\section{Statistical analysis}

The association of continuous variables was assessed using the non-parametric test for two independent samples. P-values smaller then 0.05 were considered statistically significant.

\section{Results}

$\mathrm{CD}$ expression in the tumor cells was identified in all cases of our series. High CD expression in the tumor cells was observed in 1 case $(5.3 \%)$ of $\mathrm{AD}, 2$ cases $(8.7 \%)$ of $\mathrm{M}$, 10 cases $(35.7 \%)$ of SM, 7 cases $(43.8 \%)$ of MP and in 15 cases (38.4\%) of SS (Table 1). There was a positive correlation between high $C D$ expression of $M$ and $S M(p<0.05)$ samples, but there was no correlation with the depth grading of tumor invasion. According to Duke's staging, high CD expression in the tumor cells was observed in 9 cases $(45 \%)$ of Duke's A, 13 cases (43.3\%) of Duke's B, and in 9 cases (40.3\%) of Duke's C (Table 2). There was no correlation between the different Duke's stages.

$\mathrm{CD}$ expression in the stromal cells was also present in all the specimens of our series. High CD expression in the stromal cells was observed in 1 case $(5.3 \%)$ of $\mathrm{AD}, 1$ case (4.3\%) of M, 12 cases (42.9\%) of SM, 12 cases (75\%) of MP, and in 27 cases $(69.2 \%)$ of SS (Table 1). There was a correlation between high CD in the stromal cells of $M$ and SM $(\mathrm{p}<0.01)$ samples and also SM and MP $(\mathrm{p}<0.05)$. However, as for the tumor cells, there 
Table 3. Relationship between Depth of Invasion and Lymph Node Metastasis

\begin{tabular}{cccc}
\hline & \multicolumn{3}{c}{ Depth of invasion } \\
\cline { 2 - 4 } & $\mathrm{SM}$ & MP & SS \\
\hline number & 17 & 16 & 39 \\
$\mathrm{~N}(+)$ & $1(5.9 \%)$ & $2(12.5 \%)$ & $17(43.6 \%)$ \\
\hline
\end{tabular}

Table 4. Relationship between High Cathepsin D Expression and Lymph Node Metastasis

\begin{tabular}{cccc}
\hline & \multicolumn{2}{c}{ Lymph node metastasis } \\
\cline { 2 - 4 } & $\mathrm{N}(-)$ & & $\mathrm{N}(+)$ \\
\hline number & 52 & & 20 \\
Tumor cell & $22(42.3 \%)$ & $\mathrm{NS}$ & $9(45 \%)$ \\
Stromal cell & $34(65.4 \%)$ & $\mathrm{NS}$ & $11(55 \%)$ \\
\hline
\end{tabular}

was no correlation with the depth grading of tumor invasion (Table 1). High CD in the stromal cells was observed in 12 cases $(60 \%)$ of Duke's A, 14 cases $(46.7 \%)$ of Duke's B, and in 20 cases $(90.9 \%)$ of Duke's C (Table 2). There was a correlation between Duke's B and Duke's C $(\mathrm{p}<0.01)$.

Lymph node metastasis was assessed for the 72 cases of surgical specimens, and it was observed in 1 case $(5.9 \%)$ of SM, 2 cases (12.5\%) of MP, and in 17 cases (43.6\%) of SS (Table 3). There was no correlation between high CD expression and lymph node metastasis in either tumor cells or stromal cells (Table 4).

\section{Discussion}

Carcinoma cells must penetrate the epithelial basement membrane to initiate invasive growth. In this study, we demonstrated a correlation between cathepsin D expression in colorectal tumors and both the tumor progression and depth of invasion. High CD expression in the tumor cells was less frequent in severe dysplastic adenoma (AD) and intramucosal adenocarcinomas (M), but it was enhanced in invasive carcinomas (SM, MP, $\mathrm{SS}$ ). There was a strong correlation between high $\mathrm{CD}$ expression in carcinomas of the $\mathrm{M}$ and SM. These results support previous studies in gastric adenocarcinomas that found a significant association between CD expression and the depth grading of tumor invasion ${ }^{15.16)}$. In addition, a correlation between $\mathrm{CD}$ expression and prognosis was reported in oesophageal squamous cell carcinoma ${ }^{17)}$ and breast carcinoma ${ }^{6.7,18)}$. However, until now a similar association in colorectal tumors has not been confirmed ${ }^{8-11)}$. Our findings suggest that $C D$ is highly expressed in the early stages of tumor invasion when carcinoma cells have invaded beyond the muscularis mucosa and into the submucosal stroma. We hypothesized therefore that $\mathrm{CD}$ plays an important role in degrading the basement membrane, and that $\mathrm{CD}$ expression may correlate with the invasive potential of tumor cells.

Similar results were found for CD expression in the stromal cells. There was correlation between high $\mathrm{CD}$ expression in the stromal cells of $\mathrm{M}$ and SM, and also between SM and 
Table 5. Relationship between High Oathepsin D Expression and Grading of Lymph Node Metastasis

\begin{tabular}{cccc}
\hline & \multicolumn{3}{c}{ Grading of lymph node metastasis } \\
\cline { 2 - 4 } & $\mathrm{N} 1(+)$ & $\mathrm{N} 2(+)$ or N3 $(+)$ \\
\hline number & 15 & 5 \\
Tumor Gell & $7(46.7 \%)$ & $\mathrm{NS}$ & $2(40 \%)$ \\
Stromal cell & $8(53.3 \%)$ & NS & $3(60 \%)$ \\
\hline
\end{tabular}

MP. Furthermore, there was correlation between Duke's B and Duke's C stages. There are no previous reports concerning the depth grading correlation in colorectal tumors, but Theodoropoulos et al $^{11)}$ also reported a correlation between $\mathrm{CD}$ expression in stromal cells and the Duke's stage. A relationship between CD expression in stromal cells and prognosis has also been reported in breast cancer ${ }^{7.16)}$, and further studies are needed to ascertain whether the same association exists in colorectal adenocarcinoma. Tetu et $a l^{7)}$ showed that expression of $\mathrm{CD}$ in cancer cells may not be involved in the invasive phenotype of breast cancer, instead that the enzyme derived from the reactive stromal cells may play an important role. In vitro assays by Johnson et l $^{(6)}$ and some other clinical studies ${ }^{19}{ }^{20)}$ demonstrated that an increase in $\mathrm{CD}$ activity in stromal components, such as infiltrative inflammatory cells, and not the cancer-related synthesis of the enzyme, may have a more significant biological role. Although it is known that inflammatory cell infiltration at the border of the invasive front acts as a defense mechanism against tumor invasion, inflammatory cells of the stroma inside and adjacent to the tumor mass contain various enzymes including cathepsin D that could degrade extramatrices and destroy the tissue architecture thereby facilitating tumor spread ${ }^{11}$. Graf et al $^{5)}$ reported that cathepsins discharged from inflammatory or carcinoma cells may activate other proteases. Subsequently, the degradation of extracellular matrix by such proteases may provide an effective microenvironment for proliferation and invasion of the carcinoma cells.

Lymph node metastasis was proven histologically in 72 archival surgical specimens of primary colorectal adenocarcinomas. There was no correlation between $\mathrm{CD}$ expression and lymph node metastasis for either tumor cells or stromal cells. Furthermore, no correlation was found when the cases that had lymph node metastasis were separated into two groups according to the grading of the metastasis, such as "N1 $(+)$ " and "N2 $(+)$ or N3 $(+)$ " (Table 5). In a study of breast cancer, $\mathrm{Xu}$ et al $^{21)}$ reported a significant difference in the rate of the lymphatic metastasis between $\mathrm{CD}$-positive and $\mathrm{CD}$-negative cancer cells, however, a study by Aziz et al $^{22)}$ found no significant correlation between axillary lymph node metastasis and CD positivity. As for colorectal tumors, although Arao et al ${ }^{12)}$ found a correlation between $\mathrm{CD}$ expression and lymphatic invasion, there was no correlation with lymph node metastasis. The findings from our study suggest a poor correlation between CD expression and lymph node metastasis in both tumor cells and stromal cells.

In conclusion, cathepsin $\mathrm{D}$ expression in carcinoma cells and stromal cells may reflect a potential for invasive growth of colorectal tumors. Our study findings could be useful for predicting the malignant potential of colorectal tumors obtained by endoscopic mucosal resection. 


\section{Acknowledgments}

We thank Prof. Toshio Morohoshi. Showa University School of Medicine, for critical reading of the manuscript and for his advice. We also thank Ms. Tomoko Nagai, Ms. Akiko Arakawa and Ms. Akiko Sugimoto for their technical assistance.

\section{References}

1) Stetler-Stevenson WG, Aznavoorian $S$ and Liotta LA: Tumor cell interaction with the extracellular matrix during invasion and metastasis. Anmu Rev Cell Biol 9:541-573 (1993)

2) Briozzo $\mathrm{P}$, Morisset $\mathrm{M}$, Capony $\mathrm{F}$, Rougeot $\mathrm{C}$ and Rochefort $\mathrm{H}$ : In vitro degradation of extracellular matrix with $\mathrm{Mr} 52,000$ cathepsin D secreted by breast cancer cells. Cancer Res $48: 3688-3692$. (1998)

3) Schwartz MK: Tissue cathepsins as tumor markers. Clin Chem Acta 237:67-78 (1995)

4) Maurizi M. Almadori G, Cadoni G. Scambia G, Ottaviani F, Ferrandina G, Paludetti G, D'Abramo G and Mancuso S: Cathepsin D concentration in primary laryngeal carcinoma: correlation with clinico-pathological parameters. EGFR status and prognosis. Int J Cancer 69 : 105-109 (1996)

5) Graf M, Baici A and Strauli P: Histochemical localization of cathepsin B at the invasion front of the rabbit V2 carcinoma. Lab Invest 45:587-596 (1981)

6) Johnson MD. Torri JA, Lippman ME and Dickson RB: The role of cathepsin D in the invasiveness of human breast cancer cells. Cancer Res 53:873-877 (1993)

7) Tetu B, Brisson J. Cote C. Brisson S, Potvin D and Roberge N: Prognostic significance of cathepsin-D expression in node-positive breast carcinoma : an immunohistochemical study. Int J Cancer 55: 429-435 (1993)

8) Valentini AM. Pirelli H. Armentano R and Caruso ML: The immunohistochemical expression of cathepsin D in colorectal cancer. Anticancer Res 16:77-80 (1996)

9) Caruso ML and Valentini AM: Immunohistochemical p53 expression correlated to c-erbB-2 and cathepsin D proteins in colorectal cancer. Anticancer Res $16: 3813-3818$ (1996)

10) Mayer A. Fritz E. Fortelny R. Kofler K and Ludwig H: Immunohistochemical evaluation of cathepsin D expression in colorectal cancer. Cancer Invest $15: 106^{-110}$ (1997)

11) Theodoropoulos GE, Panoussopoulos D, Lazaris AC and Golematis BC: Evaluation of cathepsin D immunostaining in colorectal adenocarcinoma. J Surg Oncol $65: 242-248$ (1997)

12) Arao J, Fukui H. Ono Y, Ueda Y, Chiba $T$ and Fujimori $T$ : Immunohistochemical localization of cathepsin $D$ in colorectal tumors. Dis Colon Rectum $43: 396-401$ (2000)

13) Japanese Society for Cancer of the Colon and Rectum.: General Rules for Clinical and Pathological Studies on Cancer of the Colon. Rectum and Anus. 6th ed, Kanehara Shuppan. Tokyo (1998)

14) Ioachim EE, Goussia AC, Machera M, Tsianos EV, Kappas AM and Agnantis NJ : Immunohistochemical evaluation of cathepsin $\mathrm{D}$ expression in colorectal tumors: a correlation with extracellular matrix components, p53. pRb, bcl-2. c-erbB-2, EGFR and proliferation indices. Anticancer Res 19:2147-2155 (1999)

15) Ikeguchi M. Fukuda K. Oka S. Yamaguchi K. Hisamitsu K. Tsujitani S. Sakatani T. Ueda T and Kaibara N : Clinicopathological significance of cathepsin D expression in gastric adenocarcinoma. Oncology 61:71-78 (2001)

16) Kantsaliev AL, Kozyreva EA, Kushlinski NE. Rottenberg VI, Klimenkov AA and Vasil'ev AV: Cathepsin D activity in gastric cancer. Vopr Onkol 40:40-46 (1994)

17) Ikeguchi M, Sakatani T, Ueta T, Fukuda K, Oka S, Hisamitsu K, Yamaguchi K. Tsujitani S and Kaibara N: Correlation between cathepsin $\mathrm{D}$ expression and 553 protein nuclear accumulation in oesophageal squamous cell carcinoma. J Clin Pathol 55: 121-126 (2002)

18) Jahkola T, Toivonen T, von Smitten K, Virtanen I, Wasenius VM and Blomqvist C: Cathepsin-D. urokinase plasminogen activator and type-1 plasminogen activator inhibitor in early breast cancer: an immunohistochemical study of prognostic value and relations to tenascin-C and other factors. $\mathrm{Br} J$ Cancer 80 : 167-174 (1999)

19) Henry JA, McCarthy AL. Angus B. Westley BR, May FE, Nicholson S. Cairns J, Harris AL and Horne CH: Prognostic significance of the estrogen-regulated protein, cathepsin D in breast cancer. An immunohistochemical study. Cancer 65:265-271 (1990)

20) Rogers S. Day CA and Fox SB: Expression of cathepsin D and estrogen receptor in male breast carcinoma. Hum Pathol 24:148-151 (1993)

21) $\mathrm{Xu} \mathrm{L}$. Shen $\mathrm{Z}$ and $\mathrm{Zhu} \mathrm{W}$ : The expression of Cath-D, c-erbB-2 and EGFR in breast cancer and its correlation to lymphatic metastasis. Zhonghua Zhong Liu Za Zhi $17: 60-63$ (1995)

22) Aziz S, Perves S. Khan S. Kayani $N$ and Rabbar $M$ : Immunohistochemical cathepsin-D expression in breast cancer: correlation with established pathological parameters and survival. Pathol Res Pract 197: $551-557$ (2001) 